\title{
MicroRNA-302 induces proliferation and inhibits oxidant-induced cell death in human adipose tissue-derived mesenchymal stem cells
}

\author{
JY Kim ${ }^{1,2,3}$, KK Shin $^{1,2,3}$, AL Lee ${ }^{1,2,3}$, YS Kim ${ }^{1,2,3}$, HJ Park ${ }^{1,2,3}$, YK Park ${ }^{1,2}$, YC Bae ${ }^{4}$ and JS Jung ${ }^{\star, 1,2,3,5}$
}

Mesenchymal stem cells (MSCs) are a heterogeneous population of cells that proliferate in vitro as plastic-adherent cells, have a fibroblast-like morphology, form colonies in vitro and can differentiate into bone, cartilage and fat cells. The abundance, ease and repeatable access to subcutaneous adipose tissue and the simple isolation procedures provide clear advantages for the use of human adipose tissue-derived mesenchymal stem cells (hASDCs) in clinical applications. We screened microRNAs (miRNAs) that affected the proliferation and survival of hADSCs. Transfection of miR-302d mimic increased cell proliferation and protected cells from oxidant-induced cell death in hADSCs, which was supported by flow-cytometric analysis. miR-302d did not affect the expression of Bcl-2 family members or anti-oxidant molecules. The Nrf2-Keap1 system, which is one of the major mechanisms for the cellular defense against oxidative stress, was not altered by transfection of miR-302d mimic. To identify the target of the miR-302d actions on proliferation and survival of $h A D S C s$, a microarray analysis was performed using miR-302d-overexpressing hADSCs. Real-time PCR analysis showed that transfection of miR-302d mimic inhibited the CDKN1A and CCL5 expression. Downregulation of CDKN1A with a specific siRNA mimicked the effect of miR-302d on hADSCs proliferation, but did not affect miR-302d-induced cell survival. Downregulation of CCL5 protected oxidant-induced cell death as miR-302d, inhibited oxidantinduced reactive oxygen species (ROS) generation and the addition of recombinant CCL5 inhibited the protective action of miR$302 \mathrm{~d}$ on oxidant-induced cell death. This study indicates that miR-302 controls proliferation and cell survival of hADSCs through different targets and that this miRNA can be used to enhance the therapeutic efficacy of hADSCs transplantation in vivo.

Cell Death and Disease (2014) 5, e1385; doi:10.1038/cddis.2014.344; published online 21 August 2014

MicroRNAs (miRNAs) are endogenous 20- to 25-nucleotidelong non-coding RNAs that bind to their targets through partial sequence complementary within the $3^{\prime}$-untranslated region (UTR) or open reading frame (ORF) of coding mRNAs. ${ }^{1}$ These binding events result in either the degradation of the mRNA or the inhibition of translation, thereby modulating the expression of miRNA targets. ${ }^{1}$ miRNAs have been implicated in many processes, including cell proliferation, apoptosis, ${ }^{2,3}$ fat metabolism, ${ }^{2}$ neuronal patterning ${ }^{4}$ and tumorigenesis. ${ }^{5}$ miR-302 is a family of eight miRNAs, which includes miR302a, miR-302a*, miR-302b, miR-302b*, miR-302c, miR$302 c^{*}$, miR-302d and miR-367. The first seven of these miRNAs constitute the miR-302 family and have a highly conserved sequence. These miRNAs are highly expressed in embryonic stem cells (ESCs) and induced pluripotent stem cells (iPSCs), and their expression levels rapidly decline as pluripotent stem cells begin to differentiate. ${ }^{6}$ These observations suggest that the miR-302 family of miRNAs may have a role in the maintenance of pluripotency or self-renewal.
Recent studies have shown that the ESC-specific cell cycleregulating (ESCC) family of miRNAs, which includes miR-302, enhances the reprogramming of mouse and human somatic cells to iPSCs. ${ }^{7-9}$ miR-302 is also expressed in various normal cell types. Kumar et al. ${ }^{10}$ reported that miR-302 levels were significantly decreased in quiescent and irradiated AG01522 normal human fibroblast (NHF) cells, which indicate a regulatory role for miR-302 in fibroblasts quiescence and proliferation. Kang et al. ${ }^{11}$ showed that miR-302 targets the $3^{\prime}$ - UTR of type II BMP receptor transcripts and leads to the downregulation of BMP signaling in human primary pulmonary artery smooth muscle cells. Recent studies have shown that miR-302 targets epigenetic regulators (AOF1/2, MECP1p66, MECP2 and MBD2), ${ }^{7}$ cell-cycle regulators (Cyclin D1/D2, CDK2, BMI-1 and PTEN), ${ }^{12,}{ }^{13}$ TGF- $\beta$ regulators (Lefty1/2 and TGFBR2), ${ }^{8,14}$ BMP inhibitors (DAZAP2, SLAIN1, and TOB2) ${ }^{12}$ and NR2F2. ${ }^{15}$ Most studies about the role of miR302 have been done in ESCs, but the function of miR-302 in mesenchymal stem cells (MSCs) has not been studied.

\footnotetext{
${ }^{1}$ Department of Physiology, School of Medicine, Pusan National University, Yangsan 626-870, Korea; ${ }^{2}$ Medical Research Center for Ischemic Tissue Engineering, Pusan National University, Yangsan 626-870, Korea; ${ }^{3}$ BK21 Medical Science Education Center, School of Medicine, Pusan National University, Yangsan 626-870, Korea; ${ }^{4}$ Department of Plastic Surgery, School of Medicine, Pusan National University, Pusan 602-739, Korea and ${ }^{5}$ Medical Research Institute, Pusan National University, Pusan 602-739, Korea

${ }^{*}$ Corresponding author: JS Jung, Department of Physiology, School of Medicine, Pusan National University, Beomeo-ri, Mulgeum-eup, Yangsan-si, Gyeongsangnam-do 626-870, Korea. Tel: + 8251510 8071; Fax: + 8251510 8076; E-mail: jsjung@ pusan.ac.kr

Abbreviations: MSCs, mesenchymal stem cells; hASDCs, human adipose tissue-derived mesenchymal stem cells; miRNAs, microRNAs; UTR, untranslated region; ORF, open reading frame; ESCs, embryonic stem cells; iPSCs, induced pluripotent stem cells; ESCC, embryonic stem cell-specific cell cycle-regulating; ROS, reactive oxygen species; $\mathrm{CoCl}_{2}$, cobalt chloride; SIN-1, 3-morpholinosydnonimine hydrochloride; SOD, superoxide dismutase; CAT, catalase; GPX, glutathione peroxidase; GST, glutathione S-transferase; HO-1, haemoxygenase-1

Received 20.1.14; revised 07.7.14; accepted 16.7.14; Edited by R De Maria
} 
Adipose tissue-derived mesenchymal stem cells (ADSCs) share many of the characteristics of their counterparts in bone marrow, including an extensive proliferative potential and the ability to differentiate toward adipogenic, osteogenic, chondrogenic and myogenic lineages. ${ }^{16-18}$ We have shown that miRNAs control the proliferation and differentiation of hADSCs. ${ }^{19,20}$ In this study, we therefore examined the role of miR-302 in hADSCs proliferation and reactive oxygen species (ROS)-induced cell death. Our results showed that miR-302 increases the proliferation of hADSCs and inhibits their oxidant-induced cell death, which may be mediated by targeting CDKN1A and CCL5.

\section{Results}

miR-302s promote proliferation of human MSCs. Figure 1a shows that miR-302 members (302a, 302b, 302c, and 302d) share a high sequence homology, differing only in the $3^{\prime}$ hexanucleotides. We determined the effect of miR-302 on the proliferation of MSCs. Direct cell counting showed that the transfection of miR-302a, b, c and d mimics in hADSCs (Figure 1b) and human bone marrow MSCs (hBMSCs) (Supplementary Figure 1a) increased their proliferation rate. The effects did not show any statistical significance among miR-302 members. Colony-forming unit (CFU) assay showed that the overexpression of miR-302s in hADSCs increased the number of CFU (Figure 1c). Cell-cycle analysis by flow cytometry demonstrated that the overexpression of miR-302 $a, b, c$ and $d$ increased the relative fraction of hADSCs in S phase but decreased the relative fraction of hADSCs in G0/G1 phase without affecting $\mathrm{G} 2 / \mathrm{M}$ phase (Figure 1d). In cell proliferation assay and cell-cycle analysis, miR-302d showed the most consistent effect among miR-302 members. Therefore, we used miR-302d in the following experiment. The transfection of mir-302d mimic did not affect osteogenic and adipogenic differentiation of hADSCs (Supplementary Figure 1b).

miR-302s protect hADSCs from oxidant-induced cell death. We discovered during these experiments that miR$302 d$-transfected cells survived well in response to stress conditions such as oligonucleotide transfection. We therefore determined the effect of miR-302s on cell survival under oxidative stress which is induced by the treatment of ROS inducers, cobalt chloride $\left(\mathrm{CoCl}_{2}\right)$ and 3-morpholinosydnonimine hydrochloride ( $\mathrm{SIN}-1)$. Because cell density affected oxidant-induced cell death in preliminary studies, we determined the effect of 100 and $200 \mu \mathrm{M}$ of $\mathrm{CoCl}_{2}$ and 5 and $10 \mathrm{mM}$ of SIN-1 on cell viability in confluence state of hADSCs. The treatment of $\mathrm{CoCl}_{2}$ and SIN-1 in hADSCs increased cell death in a dose-dependent manner after $24 \mathrm{~h}$ treatment. The transfection of miR-302s significantly protected cells from death that was induced by $\mathrm{CoCl}_{2}$ and $\mathrm{SIN}-1$ (Figure 2a). We next determined the proportion of subG1 phase in miR-302d-transfected cells with $\mathrm{CoCl}_{2}$ and $\mathrm{SIN}-1$ because apoptotic cells with fragmented DNA can be identified by their subG1-DNA content. Flow-cytometric analyses showed that the treatment of $\mathrm{CoCl}_{2}$ and $\mathrm{SIN}-1$ for $24 \mathrm{~h}$ in confluence state of hADSCs increased the proportion of subG1 phase cells, and that miR-302d transfection decreased the subG1 population in the presence of $\mathrm{CoCl}_{2}$ and SIN-1 (Figure 2b; Supplementary Figure 2). Annexin V staining, which is an early hallmark of apoptotic cell death, ${ }^{21}$ showed that transfection of miR-302d mimic decreased the proportion of Annexin $\mathrm{V}(+)$, propidium iodide $(\mathrm{PI})(+)$ cells in the presence of $100 \mu \mathrm{M} \mathrm{CoCl}_{2}$ and $5 \mathrm{mM} \mathrm{SIN-1}$ in hADSCs (Figure 2c). We then determined the effects of miR-302d on ROS generation by $\mathrm{H}_{2}$-DCFDA, which detect the overall oxidative stress including hydrogen peroxide and hydroxyl radicals. miR-302d transfection significantly decreased the generation of ROS by $100 \mu \mathrm{M} \mathrm{CoCl} 2$ or $5 \mathrm{mM} \mathrm{SIN-1}$ in hADSCs (Figure 2d), indicating that the protective action of miR-302 on oxidant-induced cell death may be related to the inhibition of ROS generation.

Pro- and anti-apoptotic Bcl-2 members and anti-oxidant mechanisms are not involved in the protection effect of miR-302d. To investigate the molecular mechanisms of the miR-302d-induced protection of cell death, we examined the expression of several apoptosis regulatory proteins. Western blot analysis of the anti-apoptotic proteins $\mathrm{Bcl}-2$ and $\mathrm{Bcl}-\mathrm{X}_{\mathrm{L}}$ and pro-apoptotic proteins Bad, Bak and Bax showed that the expression of these proteins was not altered by the transfection of miR-302d (Supplementary Figure 3). We next determined the expression of anti-oxidant molecules in hADSCs. Real-time PCR analysis showed that the transfection of miR-302d did not affect the expression of a number of anti-oxidant molecules, including superoxide dismutase $(S O D)$, catalase $(C A T)$, glutathione peroxidase $(G P X)$ and glutathione S-transferase (GST). We also determined the expression of anti-oxidant genes in the presence of $100 \mu \mathrm{M}$

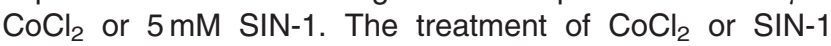
increased the expression of SOD1, SOD2, GPX1, GPX4, GST omega 1, and the transfection of miR-302d inhibited $\mathrm{CoCl}_{2}$-induced increase in SOD1 and SOD2 (Supplementary Figure 4a). Another important anti-oxidant mechanism is controlled by the Keap1/Nrf2 pathway. ${ }^{22}$ We assessed the mRNA expression of Nrf2 and Keap1 by real-time PCR and we did not observe a change in the expression of these genes (Figure 3a). The treatment of $\mathrm{CoCl}_{2}$ increased hemoxygenase-1 (HO-1) expression, one of the major antioxidant enzyme and its expression is regulated by $\mathrm{Nrf} 2,{ }^{23}$ but the quantitation of western blot experiments showed that the transfection of miR-302d did not affect HO-1, Nrf2, phospho Nrf2 or Keap1 levels in the absence or presence of $100 \mu \mathrm{M}$ $\mathrm{CoCl}_{2}$ (Figure 3b). The downregulation of Nrf2 expression by the specific siRNA (Figure 3c) also did not affect miR-302dinduced protection of $\mathrm{CoCl}_{2}$-induced cell death (Figure $3 \mathrm{~d}$ ).

Downregulation of $C D K N 1 A$ by miR-302d promotes the proliferation of hADSCs, but does not protect oxidantinduced cell death. To determine the targets of miR-302d in hADSCs, we searched for candidate gene targets using the miRWalk database, which allows for the search for interaction information from eight established miRNA target prediction programs (RNA22, miRanda, miRDB, TargetScan, RNAhybrid, PITA, PICTAR and Diana-microT). We also examined miR-302d-induced changes in gene expression of hADSCs by microarray analysis. We found 23 genes, which regulate cell cycle or oxidative stress, among 300 genes of 

Members of the miR-302 cluster

miR-302a 3 ' - AGUGGUUUUGUACCUUCGUGAAU - 5

miR-302b $3^{\prime}$ - GAUGAUUUUGUACCUUCGUGAAU - $5^{\prime}$

miR-302c 3' - GGUGACUUUGUACCUUCGUGAAU - 5'

miR-302d 3 ' - UGUGAGUUUGUACCUUCGUGAAU - 5'

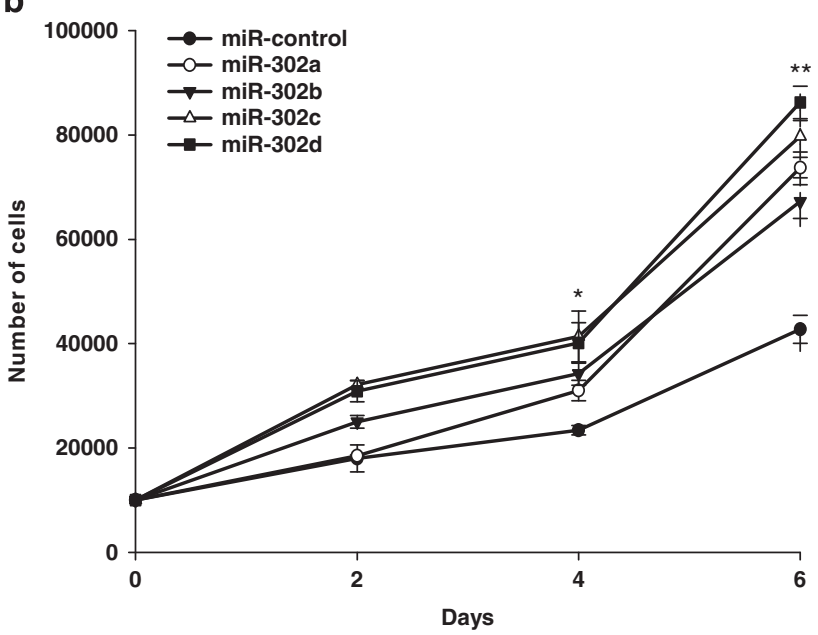

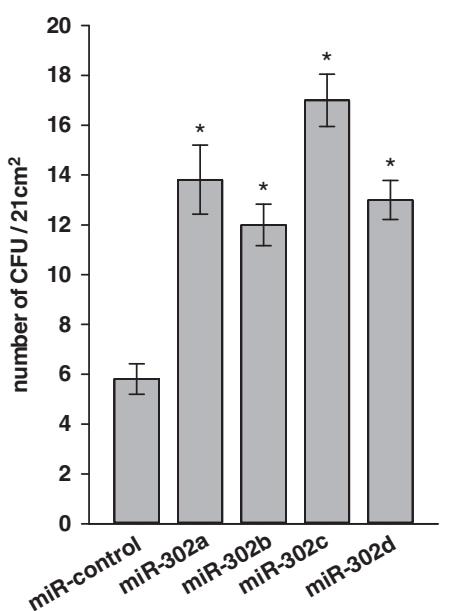

d

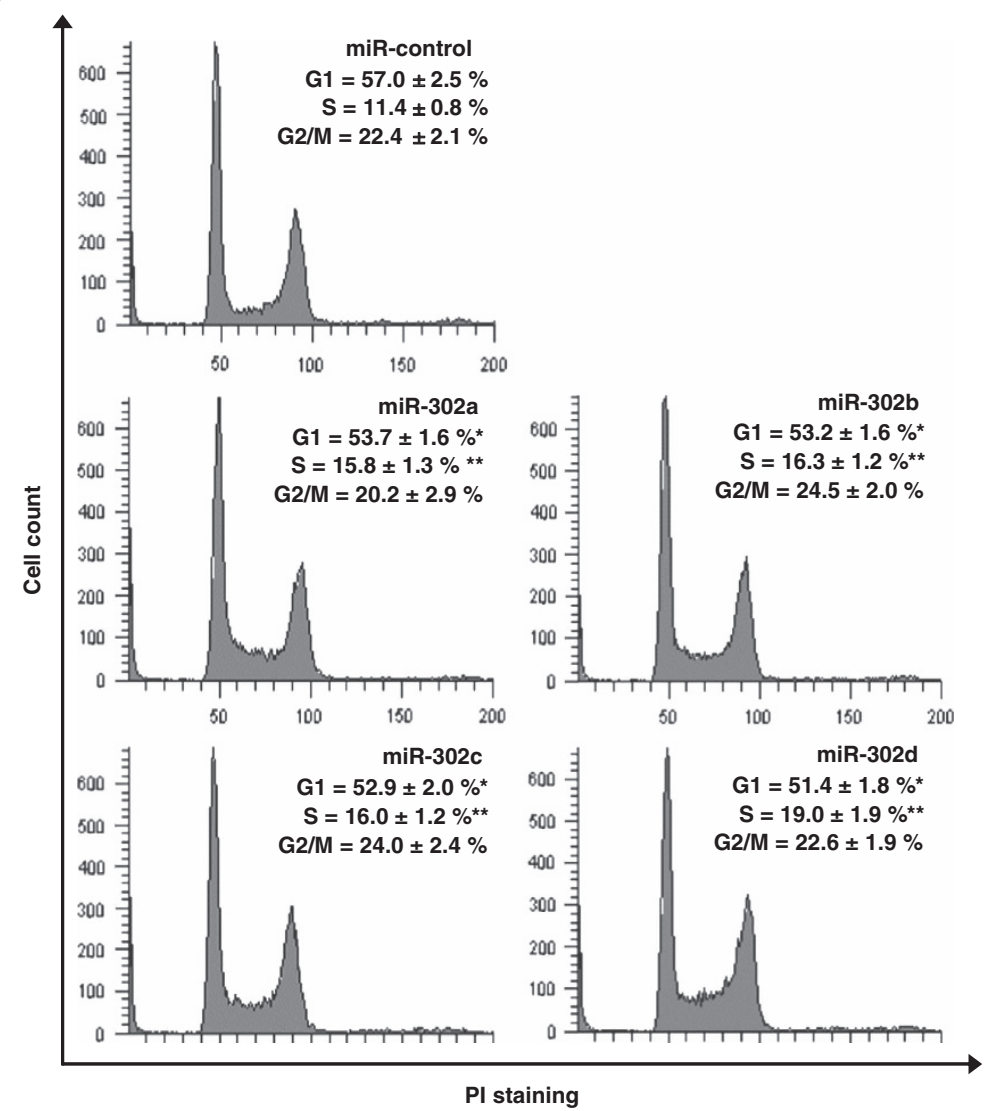

Figure 1 miR-302 regulates cell proliferation and cell-cycle progression. (a) Sequence alignment of human miR-302 family miRNAs. (b) Effect of miR-302 on proliferation of hADSCs. hADSCs were transfected with miR-control or miR-302, and proliferation was then assessed. Cells were counted at different time points. (c) CFU assay of transfected hADSCs was performed by plating 60 cells on a 60 -mm culture dish. The colonies were counted at 7 days after plating. ${ }^{*} P<0.05,{ }^{\star *} P<0.01$ versus miR-control. (d) Cell-cycle analysis of miR-control- and miR-302-transfected hADSCs. Forty-eight hours post transfection, cells were analyzed by the FACS to determine the cell-cycle distribution. 10000 cells were analyzed for each sample. The values represent the percentage of cells in each phase of the cell cycle. Data are shown as the mean \pm S.D. of four independent experiments 
a

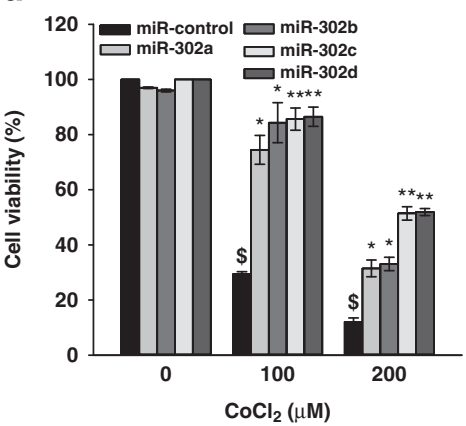

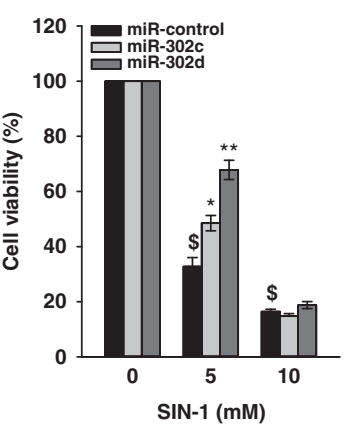

b
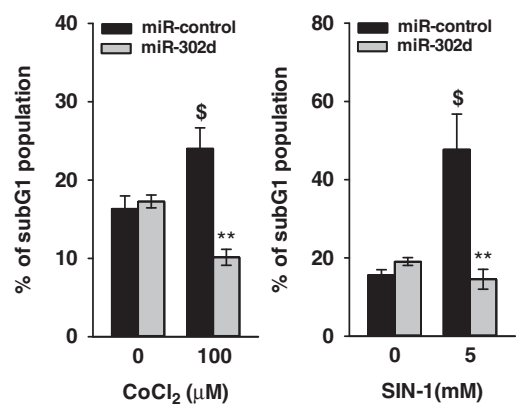

C

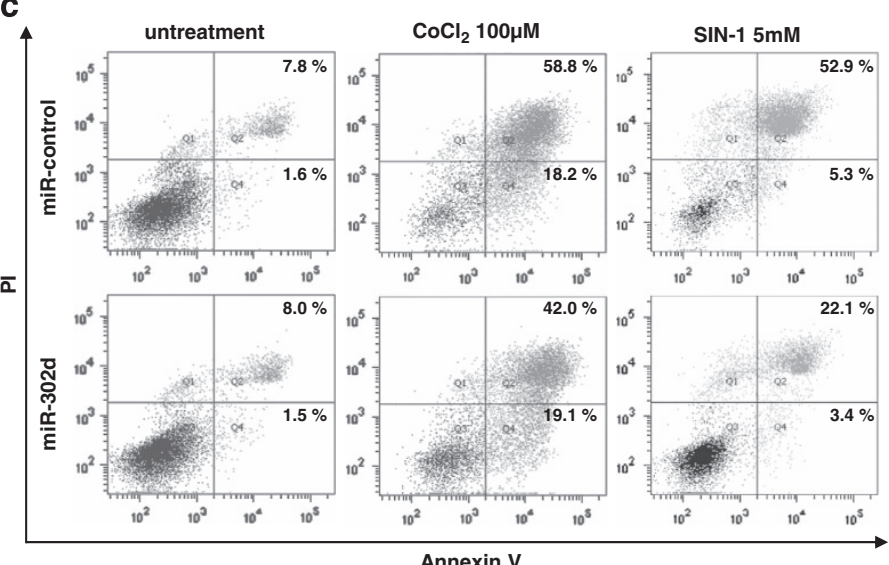

d
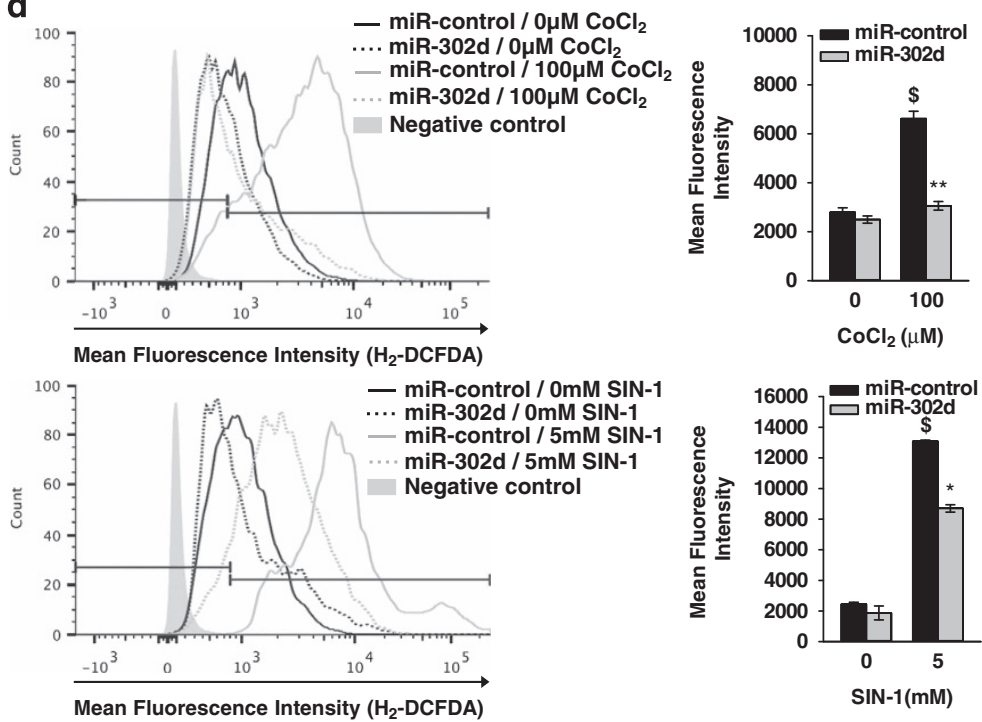

Figure 2 miR-302d inhibits oxidant-induced cell death. hADSCs were transfected with miR-control or miR-302d for $48 \mathrm{~h}$ and were then treated with $\mathrm{CoCl}_{2}$ or $\mathrm{SIN}-1$. (a) Cells were treated with various concentrations of $\mathrm{CoCl}_{2}$ or SIN-1 for $20 \mathrm{~h}$ and cell viability was assessed with trypan blue exclusion method. The results were presented

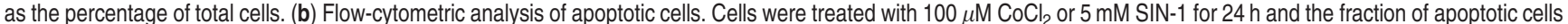
displaying a subG1 DNA content was analyzed by FACS with PI. Cells with a sub-diploid DNA content (subG1) were considered to be apoptotic. (c) Analysis of apoptotic cells with Annexin V staining. Cells were treated with the indicated oxidant for $16 \mathrm{~h}$. The fraction of apoptotic cells was analyzed by flow cytometry after the cells were stained with both Annexin V-FITC and PI. (d) Measurement of intracellular ROS generation using $\mathrm{H}_{2}$-DCFDA staining. The negative control is unstained cells. ROS level is presented as the percentage of fluorescence intensity of the stained, control cells (right panel). ${ }^{*} \mathrm{P}<0.05,{ }^{* *} P<0.01$ versus $\mathrm{CoCl}_{2}$ or $\mathrm{SIN}-1$ treated miR-control. ${ }^{\$} P<0.05$ versus untreated control. Data are shown as the mean \pm S.D. of three independent experiments

which expression was downregulated $>2$-fold (Table 1). Among the predicted targets, we focused on CDKN1A (also known as p21), because it increases in response to oxidative stress $^{24}$ and has a major role in cell-cycle arrest. ${ }^{25}$ Real-time PCR and western blot analysis showed that the transfection of miR-302d mimic decreased CDKN1A (also p21 
a

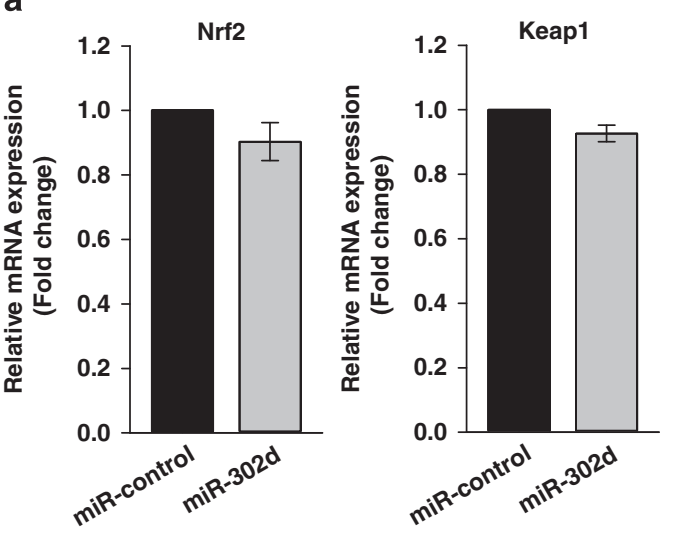

b
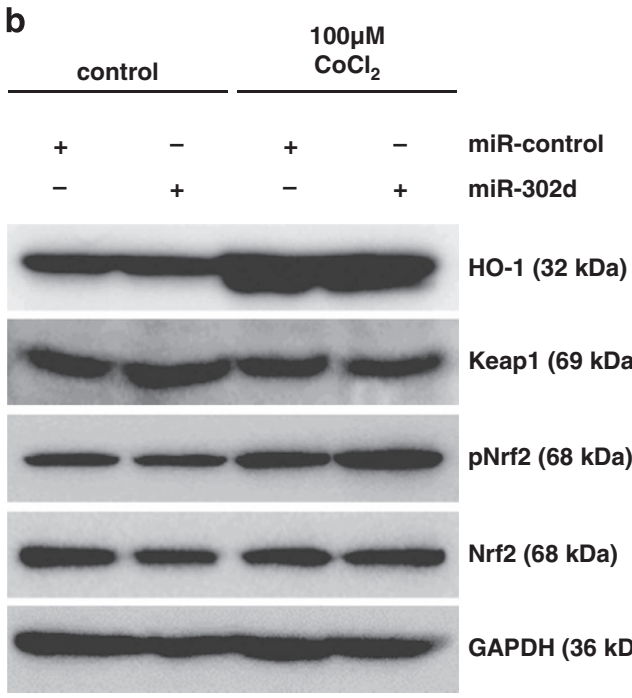

pNrf2 (68 kDa)

Nrf2 (68 kDa)

GAPDH (36 kDa)

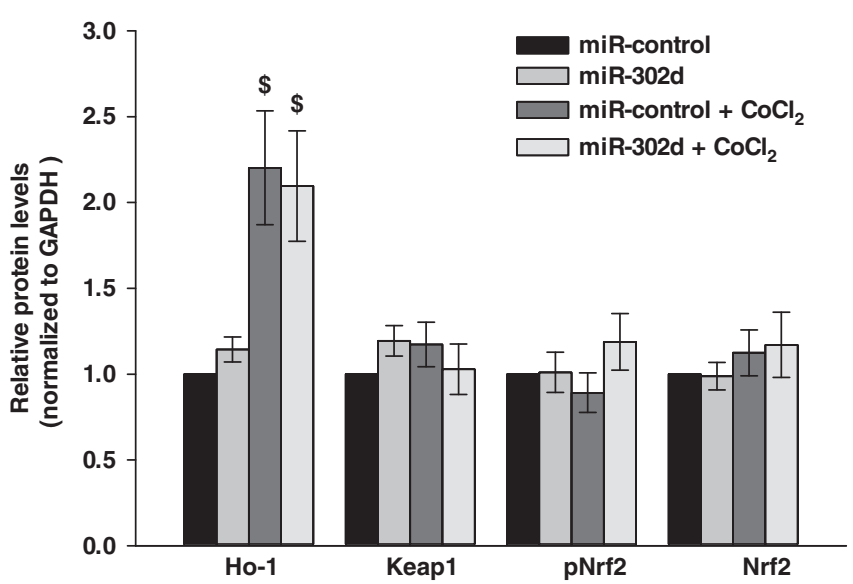

C

d
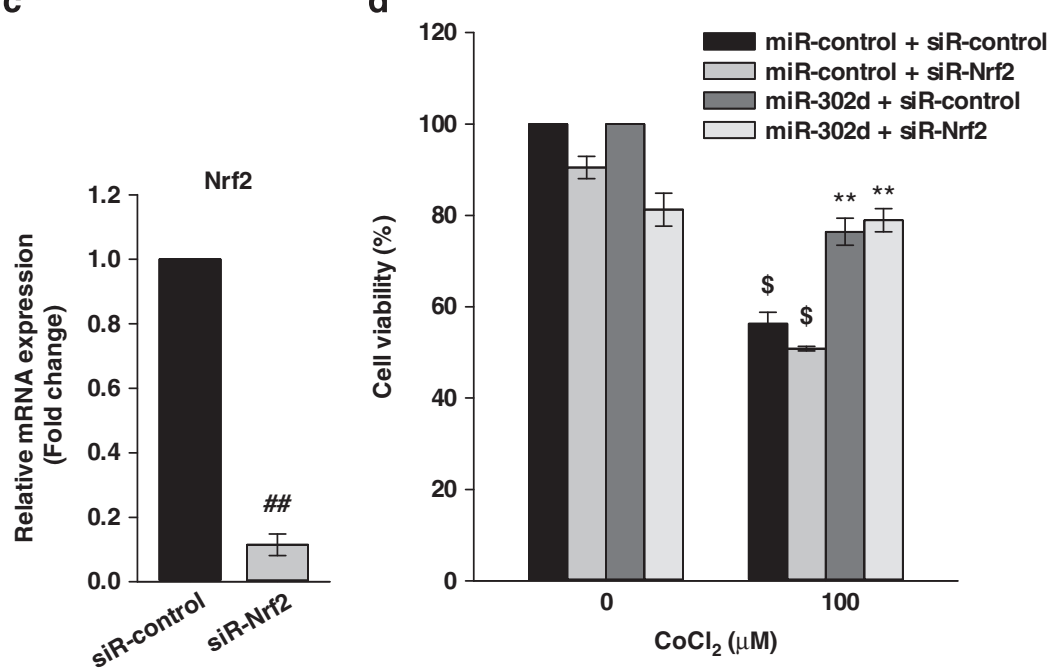

Figure 3 The protective effect of miR-302d on oxidant-induced cell death is not associated with the Keap1/Nrf2 pathway. (a) The expression of Nrf2 and Keap1 mRNA in miR-302d-transfected hADSCs was assessed by real-time PCR. (b) Western blot analysis was performed with the indicated antibodies. Protein was isolated from miR-302d-transfected hADSCs following $\mathrm{CoCl}_{2}$ exposure for $20 \mathrm{~h}$. The protein expressions were quantified and shown as the ratio of untreated miR-control (right panel). (c) Downregulation of Nrf2 expression by transfection of siR-Nrf2 was confirmed by real-time PCR. (d) Effect of Nrf2 siRNA on $\mathrm{CoCl}_{2}$-induced cell death. siR-control or siR-Nrf2 was transfected into miR-302d-transfected hADSCs. Following treatment with $\mathrm{CoCl}_{2}$, cell viability was assessed. ${ }^{\star *} P<0.01$ versus $\mathrm{CoCl}_{2}$ treated miR-control. ${ }^{\#} P<0.01$ versus siR-control. ${ }^{\$} P<0.05$ versus untreated control. Data are shown as the mean \pm S.D. of three independent experiments 
Table 1 Gene expression profile of miR-302d-overexpressing hADSCs.

\begin{tabular}{|c|c|c|}
\hline Gene symbol & Gene name & Fold change \\
\hline CYBRD1 & Cytochrome b reductase 1 & -18.41 \\
\hline TGFBR2 & Transforming growth factor, beta receptor II (70/80 kDa) & -8.66 \\
\hline FOXQ1 & Forkhead box Q1 & -5.32 \\
\hline RPS6KA2 & Ribosomal protein S6 kinase, 90 kDa, polypeptide 2 & -3.32 \\
\hline ZNF25 & Zinc finger protein 25 & -3.17 \\
\hline SDC1 & Syndecan 1 & -3.03 \\
\hline TMOD2 & Tropomodulin 2 (neuronal) & -3.02 \\
\hline$\angle O X L 3$ & Lysyl oxidase-like 3 & -2.91 \\
\hline CDC2L6 & Cell division cycle 2-like 6 (CDK8-like) & -2.89 \\
\hline GPSM2 & G-protein signaling modulator 2 (AGS3-like, C. elegans) & -2.87 \\
\hline VLDLR & Very low density lipoprotein receptor & -2.72 \\
\hline TNFRSF10B & Tumor necrosis factor receptor superfamily, member $10 \mathrm{~b}$ & -2.71 \\
\hline PON2 & Paraoxonase 2 & -2.68 \\
\hline SCD5 & Stearoyl-CoA desaturase 5 & -2.38 \\
\hline OXR1 & Oxidation resistance 1 & -2.38 \\
\hline CYB5R4 & Cytochrome b5 reductase 4 & -2.27 \\
\hline SYDE1 & Synapse defective 1, Rho GTPase, homolog 1 (C. elegans) & -2.25 \\
\hline$M A F B$ & v-maf musculoaponeurotic fibrosarcoma oncogene homolog B (avian) & -2.22 \\
\hline CDKN1A & Cyclin-dependent kinase inhibitor 1 A (p21, Cip1) & -2.21 \\
\hline SLFN11 & Schlafen family member 11 & -2.19 \\
\hline COX7A1 & Cytochrome c oxidase subunit VIla polypeptide 1 (muscle) & -2.15 \\
\hline HMOX1 & Heme oxygenase (decycling) 1 & -2.12 \\
\hline PLOD2 & Procollagen-lysine, 2-oxoglutarate 5-dioxygenase 2 & -2.09 \\
\hline
\end{tabular}

Transfection of miR-302d significantly downregulated 23 cell-cycle and oxidative stress-related genes compared with miR-control-transfected cells

expression) expression, and that the transfection of miR302d inhibitor increased CDKN1A (also p21 expression) expression (Figures $4 \mathrm{a}$ and $\mathrm{c}-\mathrm{e}$ ). To determine the role of $C D K N 1 A$ in the action of miR-302d, we examined the effect of CDKN1A siRNA on proliferation and cell death. The transfection of CDKN1A siRNA decreased its expression significantly at mRNA and protein levels (Figures 4b, d, and e), increased the proliferation of hADSCs (Figure 4f), and mitigated the modulation of hADSCs proliferation by miR302d inhibitor (Figure $4 \mathrm{~g}$ ). We also determined the effect of miR-302d on the expression of cell cycle-related genes. The transfection of miR-302d increased the expression of CDK2, CDK6, cyclin A2, cyclin B1, cyclin B2 and cyclin D3 without affecting the expression of cyclin D1 and cyclin E1 (Supplementary Figure 5). In contrast, the transfection of CDKN1A siRNA did not affect $\mathrm{CoCl}_{2}$ - and $\mathrm{SIN}$-1-induced cell death in hADSCs (Figure 4h). We determined the effect of miR-302d on CDKN1A expression in the absence or presence of $\mathrm{CoCl}_{2}$ and $\mathrm{SIN}-1$. The treatment of $\mathrm{CoCl}_{2}$ and SIN-1 increased CDKN1A expression in control miRNA or miR-302d-transfected cells (Figure 4i). To determine whether miR-302d directly binds to 3'UTR of CDKN1A, we used luciferase reporter vector that contains a putative miR-302d binding sequence of CDKN1A 3'UTR. Cells were transfected with a luciferase construct in which the miR-302 target site from the CDKN1A 3'UTR was inserted exhibited significantly lower luciferase activity in miR-302 mimic-transfected hADSCs than in control miRNA-transfected cells (Figure 4j), indicating that miR-302d directly targets 3'UTR of CDKN1A.

miR-302d-mediated repression of CCL5 reduces oxidant-induced cell death in hADSCs. CCL5, which was one of important target of miR-302s-induced regulation of human fibroblasts proliferation, ${ }^{10}$ has been reported to be activated by xanthine oxidase-mediated ROS production in murine mesangial cells ${ }^{26}$ and to produce hydrogen peroxide in human eosinophils. ${ }^{27}$ Real-time PCR analysis and enzyme-linked immunosorbent analysis (ELISA) showed that transfection of miR-302d mimic suppressed CCL5 mRNA levels and protein levels in hADSCs (Figures $5 a$ and $b$ ). Then, we determined the effect of the downregulation of CCL5 expression. The transfection of CCL5 SiRNA in hADSCs inhibited CCL5 mRNA and protein levels (Figures $5 \mathrm{c}$ and d). Downregulation of CCL5 expression did not affect basal and miR-302-induced increase in hADSCs proliferation (Figure 5e). We next tested whether the protective effects of miR-302 against oxidant injury were mediated by the suppression of CCL5 expression. Cell viability assay revealed that downregulation of CCL5 via siR-CCL5 decreased $\mathrm{CoCl}_{2}$ - and SIN-1-induced cell death like transfection of miR-302d, and cotransfection of miR-302d and CCL5 siRNA further increased cell viability (Figure 5f). Using realtime PCR analysis (Figure $5 \mathrm{~g}$ ) and ELISA (Figure $5 \mathrm{~h}$ ), we confirmed that $\mathrm{CoCl}_{2}$ and SIN-1 treatment upregulated CCL5 expression in hADSCs, and that transfection of miR-302d reduced oxidant-induced increase in CCL5 expression and the CCL5 siRNA and miR-302d-cotransfected cells showed lower CCL5 protein level than that of miR-302dtransfected cells. Transfection with siR-CCL5 also decreased $\mathrm{CoCl}_{2-}$ and SIN-1-induced ROS generation (Figure 5j). To confirm the role of CCL5 in miR-302d-induced protection of cell death, we determined the effect of recombinant CCL5 (Figure 5i). The addition of recombinant CCL5 $(5 \mu \mathrm{g} / \mathrm{ml})$ increased $\mathrm{CoCl}_{2}$-induced cell death and inhibited miR-302induced protection of $\mathrm{CoCl}_{2}$-induced cell death in hADSCs. Bioinformatic analysis showed that 3'UTR of CCL5 mRNA contains a putative target site for miR-302d, as described by Kumar et al. ${ }^{10}$ To determine whether miR-302d directly binds to 3'UTR of CCL5, we used luciferase reporter vector that contains a putative miR-302d binding sequence of CCL5 3'UTR. Cells were transfected with a luciferase construct in 

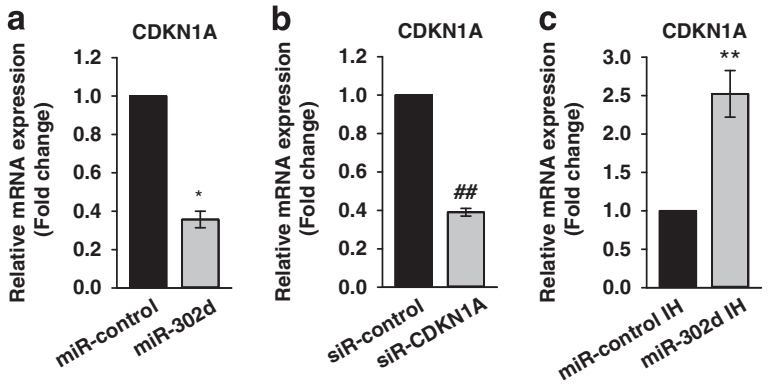

d

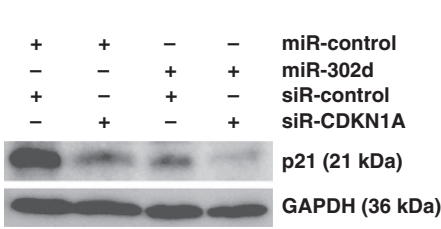

e

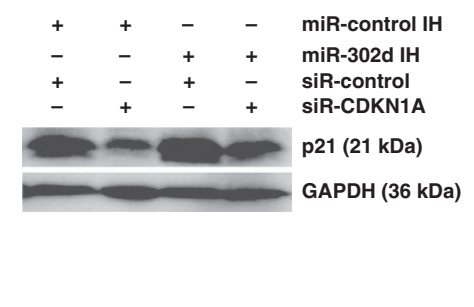

f

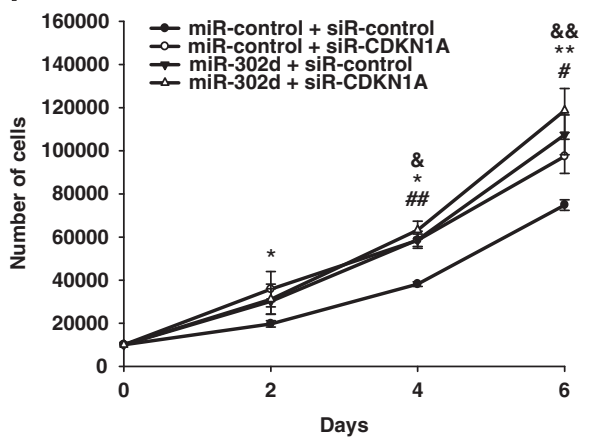

g

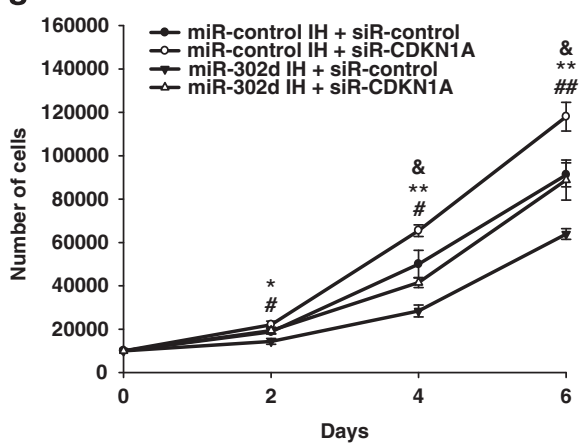

h
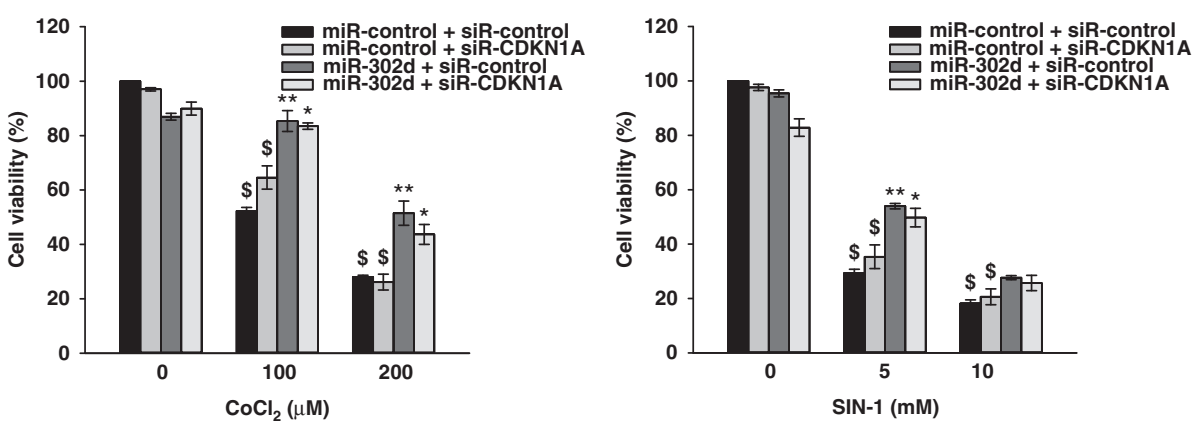

i

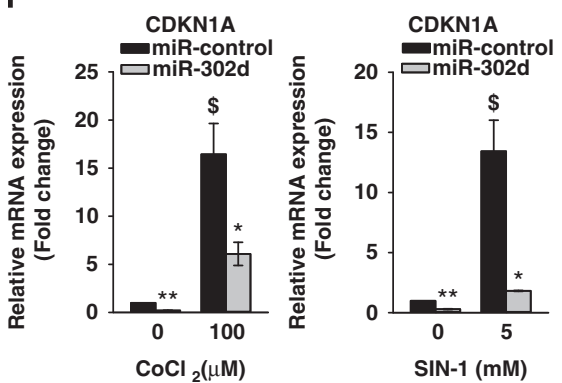

j

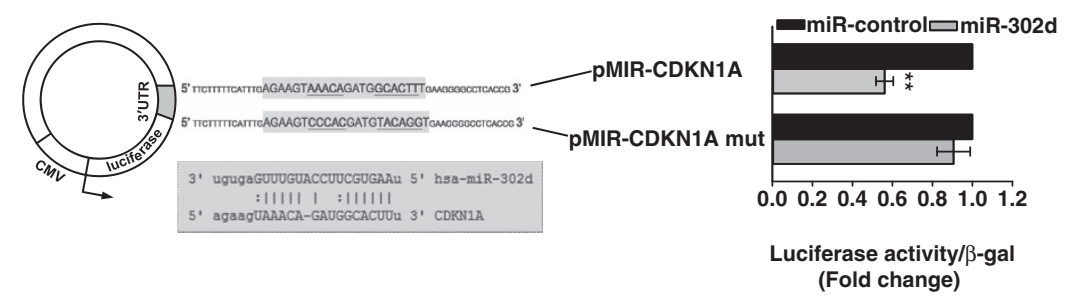

Figure 4 The expression level of CDKN1A is involved in miR-302d-induced proliferation in hADSCs. (a and b) Downregulation of CDKN1A mRNA expression. Forty-eight hours after transfection with indicated miRNA (a) or siRNA (b), cells were harvested for measurement of mRNA levels by real-time PCR. ${ }^{*} P<0.05$ versus miR-control. ${ }^{\# \#} P<0.01$ versus siR-control. (c) The increased expression of CDKN1A in miR-302d inhibitor (IH)-transfected hADSCs. ${ }^{*} P<0.01$ versus miR-control IH. (d and $\left.\mathbf{e}\right)$ Downregulation or upregulation of p21 (a protein that in humans is encoded by the CDKN1A gene) expression. Cells were transfected with indicated miRNA after transfection with siR-control or siR-CDKN1A. Forty-eight hours after cotransfection of miRNA and siRNA, the protein levels of p21 were analyzed by western blotting. (f and $\mathbf{g}$ ) Effect of CDKN1A siRNA on proliferation. hADSCs with or without silencing of CDKN1A expression were transfected with miR-control or miR-302d (f), and with miR-control IH or miR-302d IH (g). Cells were counted at different time points. ${ }^{*} P<0.05$, ${ }^{* *} P<0.01$ versus miR-control (or miR-control IH). ${ }^{\#} P<0.05$, ${ }^{\# \#} P<0.01$ versus siR-control. ${ }^{\&} P<0.05$ versus miR-302d (or miR-302dIH)-transfected siR-control. (h) Effect of CDKN1A siRNA on oxidant-induced hADSCs death. Cells were transfected with siR-CDKN1A and/or miR-302d and were then treated with $\mathrm{CoCl}_{2}$ or SIN-1. Cell viability was determined by trypan blue exclusion. (i) The CDKN1A mRNA level in oxidant-treated hADSCs after transfection of miR-302d. The CDKN1A mRNA level was confirmed by real-time PCR at $48 \mathrm{~h}$ after transfection. ${ }^{*} P<0.05,{ }^{*} P<0.01$ versus $\mathrm{CoCl} 2$ or $\mathrm{SIN}-1$ treated miR-control. ${ }^{\$} P<0.05$ versus untreated control. (j) Schematic diagram of luciferase reporter vector. The CDKN1A 3'UTR sequences containing the predicted miR-302d binding site or mutated binding site (mut) were inserted into the PMIR-REPORT vector. The box shows the sequence alignment of miR-302d and its predicted binding site in 3'UTR of CDKN1A. miR-control or miR-302d was cotransfected with pMIR-CDKN1A or pMIR-CDKN1A mut luciferase constructs into hADSCs, respectively. Relative luciferase activities were analyzed at $72 \mathrm{~h}$ post transfection. ${ }^{\star \star} P<0.01$ versus miR-control. Data are represented the mean \pm S.D. of four independent experiments 
which the miR-302 target site from the CCL5 3'UTR was inserted exhibited similar luciferase activity in miR-302 mimictransfected hADSCs with that in control miRNA-transfected cells (Supplementary Figure 6).

\section{Discussion}

miR-302s are highly expressed in ESCs and have an important role in the self-renewal and pluripotency of ESCs.
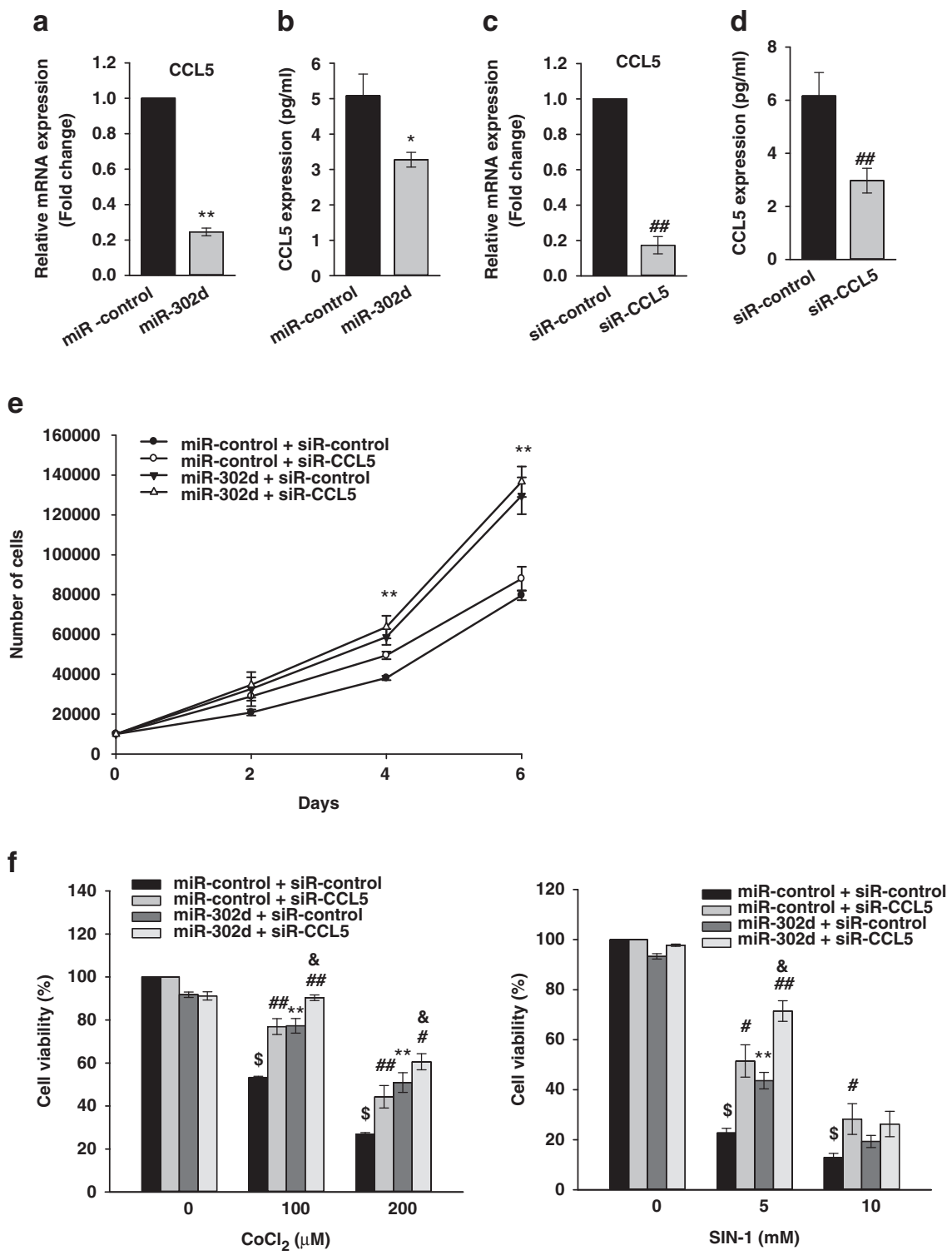

g
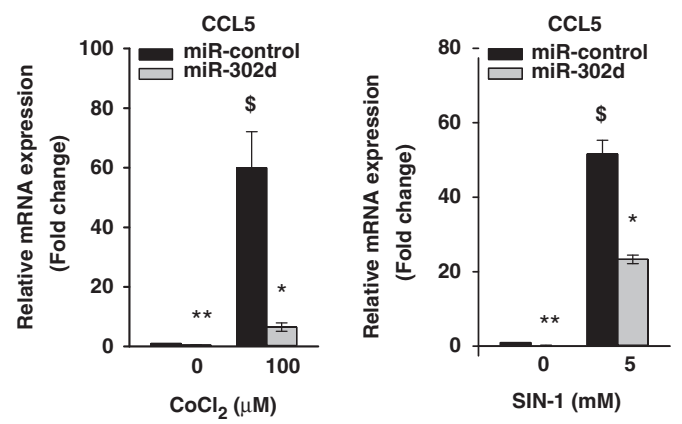

Figure 5 (Continued) 
h

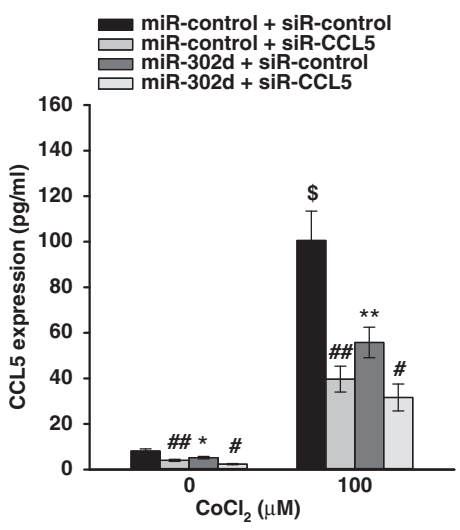

i

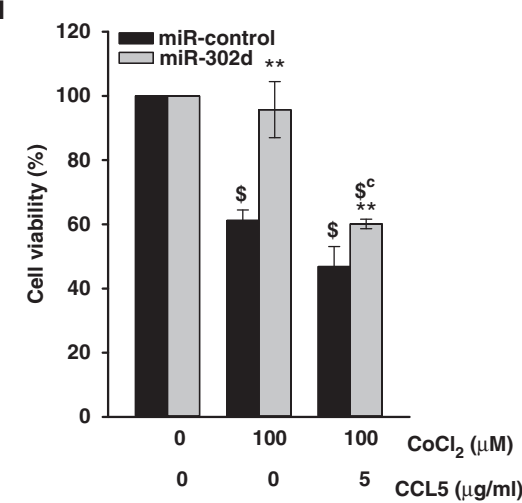

j
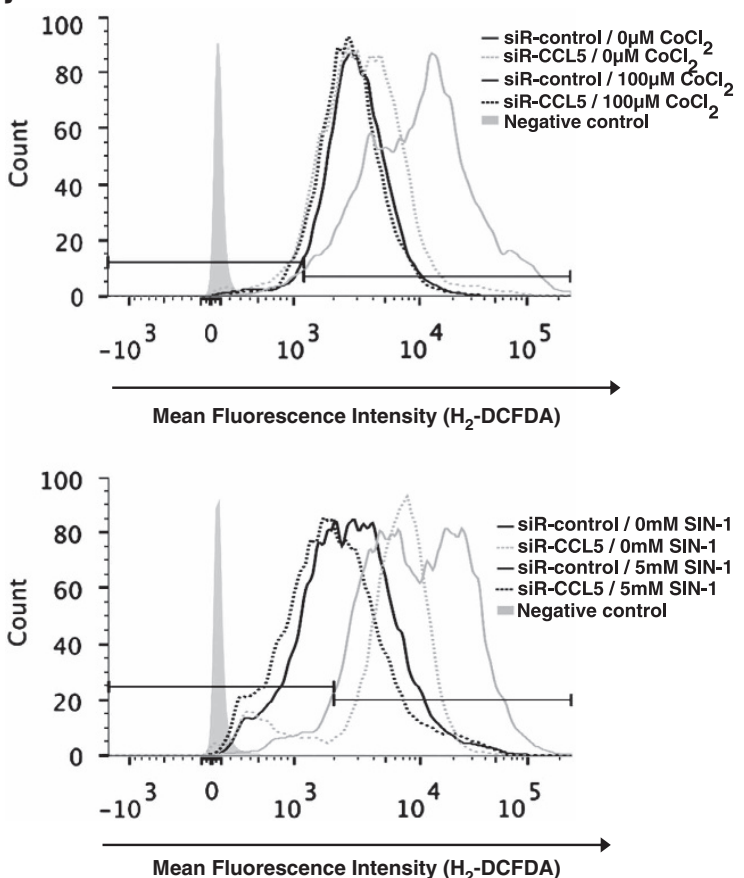

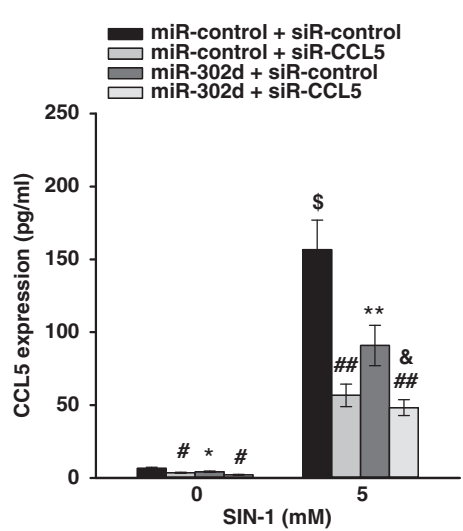


However, the effect of miR-302 on cell proliferation is variable depending on the cell type. miR-302 suppressed cell proliferation in various cancer cells $\mathrm{s}^{28-30}$ and tumorigenicity of human ES cells, ${ }^{15}$ whereas the overexpression of miR-302 increased the fraction of S-phase cells in an NHF cell line. ${ }^{10}$ Cell counting and cell-cycle analysis in this study showed that the transfection of miR-302 mimic increased the proliferation of hADSCs and the fraction of S phase, but decreased Go/G1 phase (Figure 1). A similar change by miR-302a in cell-cycle analysis showed in NHFs, ${ }^{31}$ although they have not determined whether overexpression of miR-302a increased the proliferation of NHFs. We also observed an increase in expression of cyclin $A$, cyclin $B, C D K 2$ and CDK6 mRNA (Supplementary Figure 5). In contrast, miR-302 has been reported to have multiple cell-cycle targets in ESCs, including the stem cell-related genes Oct4/Sox2 and NR2F2, cyclin D1, CDK2 and CDKN1A. ${ }^{8,13,15}$ This discrepancy can be explained by the findings that miRNAs act independently in different cell types, perhaps through the repression of different target genes. $^{20}$ The final biological effects of miRNAs strongly depend on the repertoire of miRNAs, mRNA targets, and their expression level, and the same miRNA may have opposite roles in different cellular context. ${ }^{32}$ Chen et al. ${ }^{33}$ reported that mir-181 showed the differential effects on differentiation of $\mathrm{B}$ cells $\left(\mathrm{CD} 19^{+}\right)$and cytotoxic T cells $\left(\mathrm{CD} 8^{+}\right)$, which are not developmentally linked during hematopoietic lineage commitment. The pro-senescence role of miR- $20 \mathrm{a}^{34}$ and miR- $290^{35}$ in mouse embryonic fibroblasts is in contrast with their proliferative role in tumor and ESCs. ${ }^{36,37}$ All of these findings indicated that miR-302s increase proliferation of hADSCs. miR-302 has been reported to have multiple cell-cycle targets in ESCs, including the stem cell-related genes Oct4/Sox2 and NR2F2, cyclin D1, CDK2 and CDKN1A..$^{8,13,15}$ In this study, microarray analysis showed that miR-302d inhibited CDKN1A expression (Table 1), and this result was confirmed by realtime PCR and western blotting (Figures $4 a$ and $d$ ). The p21 (CIP1/WAF1) protein binds to and inhibits the activity of cyclinCDK2, -CDK1, and-CDK4/6 complexes and thus functions as a regulator of cell-cycle progression during $\mathrm{G} 1$ phase. ${ }^{38} \mathrm{~A}$ role for CDKN1A in the miR-302-induced increase in cell proliferation was supported by the findings that the downregulation of $C D K N 1 A$ expression increased the proliferation of hADSCs and blocked the action of miR-302d mimic and inhibitor in hADSCs proliferation (Figures $4 \mathrm{f}$ and $\mathrm{g}$ ). Our study using luciferase construct showed that miR-302 directly binds to 3'UTR of CDKN1A mRNA (Figure 4j). It has been shown that miR-302 binds directly to the 3'-UTR of CDKN1A mRNA in mouse ES cells ${ }^{39}$ and human ES cells. ${ }^{40}$ These data indicated that miR-302-induced proliferation in hADSCs is mediated by the targeting of CDKN1A mRNA. Kumar et al. ${ }^{10}$ reported that CCL5 has an important role in miR302-induced fibroblast proliferation. Although we also observed that miR-302d inhibited CCL5 expression, we did not observe an increase in hADSCs proliferation following transfection of CCL5 siRNA (Figure 5e). The role of CCL5 in cell proliferation is variable and depends on cell types. CCL5 increased cell proliferation in MCF-7 cells ${ }^{41}$ but inhibited proliferation in human fibroblasts. ${ }^{10}$ Thus, the discrepancy of the results may be related to the cell types that were used in these experiments.

The most important finding of this study is that miR-302 protects hADSCs from $\mathrm{CoCl}_{2}$ - and $\mathrm{SIN}-1$-induced cell death. Flow-cytometric analysis showed that miR-302d inhibited apoptotic cell death that was induced by $\mathrm{CoCl}_{2}$ and $\mathrm{SIN}$ 1 (Figures $2 \mathrm{~b}$ and $\mathrm{c}$ ). $\mathrm{CoCl}_{2}$, which is a chemical hypoxia agent, generates ROS. ${ }^{42,43} \mathrm{SIN}-1$ simultaneously produces peroxide radicals and $\mathrm{NO}$, which results in the production of peroxynitrite. ${ }^{44}$ ROS determination using fluorescent dyes showed that miR-302 transfection inhibited SIN-1- and $\mathrm{CoCl}_{2}-$ induced ROS generation and basal ROS levels (Figure 2d), indicating that the miR-302d action is related to diminution of ROS generation. In this study, the $\mathrm{CoCl}_{2}$ - and $\mathrm{SIN}$-1-induced hADSCs death was not inhibited by transfection of CDKN1A siRNA (Figure $4 \mathrm{~h}$ ), although the treatment of $\mathrm{CoCl}_{2}$ or $\mathrm{SIN}-1$ increased CDKN1A expression (Figure 4i). The role of $C D K N 1 A$ on cell death is variable according to experimental conditions. It has been reported that $C D K N 1 A$ involved in 5-aza-2-deoxycytidine-induced cell death in human prostate cancer cells, ${ }^{45}$ epigallocatechin-3-gallate-induced apoptosis $^{46}$ and C(2)-ceraminde-induced apoptosis in mouse embryonic fibroblasts. ${ }^{47}$ In contrast, CDKN1A inhibited hyperoxia-induced cell death in $\mathrm{H} 1299$ human lung adenocarcinoma cells, ${ }^{48}$ apoptosis during DNA replication fork stress, ${ }^{49}$ and shikonin-induced apoptosis. ${ }^{50}$ The negative effect of CDKN1A siRNA on oxidant-induced cell death in this experiment may also be related to incomplete knockdown of $C D K N 1 A$ expression. To exclude the role of $C D K N 1 A$ on miR-302d-mediated protection of hADSCs, we have to use complete knockdown cells of CDKN1A gene.

\footnotetext{
Figure 5 miR-302d protects hADSCs from oxidant-induced cell death through a reduction in CCL5 expression. (a and c) Downregulation of CCL5 mRNA expression by transfection of miR-302d or siR-CCL5. Forty-eight hours after transfection with miR-302d (a) or siR-CCL5 (c), cells were harvested for measurement of CCL5 mRNA levels. Real-time PCR was performed to determine the CCL5 mRNA levels. (b and d) Downregulation of CCL5 protein expression by transfection of miR-302d or siR-CCL5. Cells were transfected with miR-302d (b) or siR-CCL5 (d) for $48 \mathrm{~h}$. After another $24 \mathrm{~h}$ in serum-free growth medium, cell-culture supernatant was harvested to measure the amounts of CCL5 using the ELISA kit. (e) Effect of CCL5 siRNA on hADSCs proliferation. hADSCs with or without silencing of CCL5 expression were transfected with miR-control or miR-302d. Cells were counted at different time points. ${ }^{*} P<0.05$, ${ }^{*} P<0.01$ versus miR-control. ${ }^{\# \#} P<0.01$ versus siR-control. (f) Effect of CCL5 siRNA on oxidant-induced hADSCs death. Cells were transfected with siR-CCL5 and/or miR-302d and were then treated with $\mathrm{CoCl}_{2}$ or $\mathrm{SIN}-1$. Cell viability was determined by trypan blue exclusion. ${ }^{\star} P<0.05,{ }^{* *} P<0.01$ versus $\mathrm{CoCl}_{2}$ or $\mathrm{SIN}-1$ treated miR-control. ${ }^{\#} P<0.05$, ${ }^{\# \#} P<0.01$ versus $\mathrm{CoCl}_{2}$ or $\mathrm{SIN}-1$ treated siR-control. ${ }^{\$} P<0.01$ versus untreated control. ${ }^{\&} P<0.05$ versus miR-302d-transfected siR-control. (g) The CCL5 mRNA levels in oxidant-treated hADSCs after transfection of miR-302d were confirmed by real-time PCR. (h) The CCL5 protein levels in oxidant-treated hADSCs after transfection of miR-302d were confirmed by ELISA. ${ }^{*} P<0.05$, ${ }^{*} P<0.01$ versus miR-control. ${ }^{*} P<0.05$, ${ }^{\# \#} P<0.01$ versus siR-control. ${ }^{\$} P<0.01$ versus untreated control. ${ }^{\&} P<0.05$ versus miR-302d-transfected siR-control. (i) hADSCs were transfected with miR-302d or siRCCL5 for $48 \mathrm{~h}$, and were then cotreated with recombinant CCL5 $(5 \mu \mathrm{g} / \mathrm{ml})$ and $\mathrm{CoCl}_{2}$ for $20 \mathrm{~h}$. Cell viability was determined by trypan blue exclusion. ${ }^{* \star} P<0.01$ versus $\mathrm{CoCl}{ }_{2}$ treated miR-control. ${ }^{\$} P<0.01$ versus $\mathrm{CoCl}_{2}$ untreated control. ${ }^{\mathrm{C}} \mathrm{P}<0.01$ versus $\mathrm{CoCl}_{2}$ treated and CCL5 untreated control. (j) Effect of CCL5 siRNA on oxidant-induced ROS generation. siR-control or siR-CCL5 was transfected into hADSCs for $48 \mathrm{~h}$. Following treatment with $\mathrm{CoCl}_{2}$ or $\mathrm{SIN}^{-1}$ for $24 \mathrm{~h}$, intracellular ROS levels were quantitated by $\mathrm{H}_{2}$-DCFDA staining using FACS. The graph showed the percentage of fluorescence intensity compared with the stained control cells (right panel). ${ }^{\#} P<0.05$, ${ }^{\#} P<0.01$ versus $\mathrm{CoCl}_{2}$ or SIN-1 treated siR-control. ${ }^{\$} P<0.01$ versus untreated control. Data are represented the mean \pm S.D. of four independent experiments
} 
In this study, in addition to inhibiting CCL5 expression by miR-302d mimic (Figures $5 a$ and b), we observed that the $\mathrm{CoCl}_{2}$-induced increase in CCL5 expression was inhibited by miR302d (Figures $5 \mathrm{~g}$ and $\mathrm{h}$ ) and that CCL5 siRNA transfection resulted in a protection against $\mathrm{CoCl}_{2}$ - and $\mathrm{SIN}$-1-induced cell death (Figure 5f). The transfection of CCL5 siRNA also inhibited $\mathrm{CoCl}_{2}-$ and $\mathrm{SIN}$-1-induced ROS generation (Figure $5 \mathrm{j}$ ) and the addition of recombinant CCL5 inhibited miR-302d-induced protection about oxidant-induced cell death (Figure 5i). An ROS-induced increase in CCL5 expression was also reported in airway epithelial cells ${ }^{51}$ and a human fibroblast cell line. ${ }^{10} \mathrm{~A}$ reduction in tissue injury by CCL5 inhibition has been reported in myocardial reperfusion injury. ${ }^{52}$ All of these findings indicate that the inhibition of oxidant-induced cell death by miR-302d is mediated in part by the inhibition of CCL5. The luciferase assay using a construct which contains a putative miR-302d target site of CCL53'UTR failed to show direct binding of miR-302d to CCL5 3'UTR (Supplementary Figure 6). However, Kumar et al. ${ }^{10}$ showed that $\mathrm{miR}-302 \mathrm{a}$ overexpression inhibited luciferase activity in the experiment using a construct to which $400 \mathrm{bp}$ of 3'UTR of CCL5 was cloned. Therefore, this discrepancy may be resulted from the possibility that the construct to be used in the experiment may contain another binding site for miR-302.

The regulation of intracellular ROS levels has a critical role in maintaining stemness, the differentiation of stem cells, and the pathogenesis of stem cell-related diseases. ${ }^{53,54}$ The low level of ROS in stem cells is maintained by the high level of expression of anti-oxidant genes, enhanced DNA doublestrand break repair and the expression of heat-shock proteins. The findings of this study suggest that high levels of miR-302 in pluripotent stem cells may also contribute to anti-oxidant defense in stem cells and that regulation of redox status by miR-302 in stem cells may have important roles in the regulation of stem cell self-renewal and fate.

In conclusion, miR-302 regulates proliferation and protects against oxidant-induced cell death. These actions are mediated by the target genes CDKN1A and CCL5. The modulation of miR-302 may be a novel strategy to protect against ischemic tissue injury and/or to enhance the survival of transplanted stem cells.

\section{Materials and Methods}

Cell culture. All protocols involving human subjects were approved by the Institutional Review Board of Pusan National University. Superfluous materials were collected from four individuals undergoing elective abdominoplasty after informed consent was given by each individual. The hADSCs were isolated according to the methods described in previous studies. ${ }^{55}$ hADSCs were maintained in low-glucose DMEM with $10 \%$ fetal bovine serum, $100 \mu \mathrm{g} / \mathrm{ml}$ streptomycin and $100 \mathrm{U} / \mathrm{ml}$ penicillin in $5 \% \mathrm{CO}_{2}$ environment at $37^{\circ} \mathrm{C}$. $\mathrm{hBMSCs}$ were maintained in $\alpha$-MEM with $10 \%$ fetal bovine serum, $100 \mu \mathrm{g} / \mathrm{ml}$ streptomycin and $100 \mathrm{U} / \mathrm{ml}$ penicillin in $5 \% \mathrm{CO}_{2}$ environment at $37^{\circ} \mathrm{C}$.

Reagents. $\mathrm{CoCl}_{2}$ and SIN-1 were purchased from Sigma-Aldrich (St. Louis, MO, USA). Recombinant human CCL5 was purchased from R\&D Systems (Minneapolis, MN, USA).

miRNA, siRNA transfection. hADSCs were seeded with complete medium without antibiotics. On the following day, miR-302 (Dharmacon, Thermo Scientific, Epsom, UK) at a final concentration of $20 \mathrm{nM}$ and/or siRNA (on-TARGET plus SMART pool, Thermo Scientific, Epsom, UK) for NFE2L2 (Nrf2), CDKN1A and CCL5 at a final concentration of $100 \mathrm{nM}$ were transfected to hADSCs using DharmaFECT 1 (Thermo Scientific, Rockford, IL, USA) reagent according to the manufacturer's protocol. miRNA negative control or non-targeting siRNA was transfected as a negative control.

Proliferation and colony-forming unit assay. hADSCs were transfected with each miRNA and/or siRNA. After $48 \mathrm{~h}$ incubation, cells were seeded in 6 -well plates at a density of $1 \times 10^{4}$ cells/well. In all, 2,4 and 6 days later, the cells were trypsinized and stained with trypan blue (Sigma, St. Louis, MO, USA). The number of cells was counted using the Countess Automated Cell Counter (Invitrogen, Carlsbad, CA, USA). Sixty cells were seeded in 60-mm dishes to perform the CFU assay. The colonies were stained with crystal violet (Sigma) and counted 10 days after plating.

Induction of differentiation. Transfected hADSCs were seeded in 12-well plates at a density of $3 \times 10^{4}$ cells $/ \mathrm{cm}^{2}$. After $24 \mathrm{~h}$ incubation, adipogenic differentiation was induced by replacing with the adipogenic medium (10\% FBS, $1 \mu \mathrm{M}$ dexamethasone, $0.5 \mathrm{mM}$ 3-isobutyl-1-methylxanthine, and $200 \mu \mathrm{M}$ indomethacin in $\alpha$-MEM) for 7 days and assessed by staining with the Oil Red $O$ dye as an indicator of intracellular lipid accumulation. To induce osteogenic differentiation, cells were seeded in 12-well plates at a density of $4 \times 10^{4}$ cells/ $\mathrm{cm}^{2}$ and incubated for $24 \mathrm{~h}$ before replacing with the osteogenic medium $(10 \%$ FBS, $0.1 \mu \mathrm{M}$ dexamethasone, $10 \mathrm{mM} \beta$-glycerophosphate, and $50 \mu \mathrm{M}$ ascorbic acid in $\alpha$-MEM). After 21 days, osteogenic differentiation was determined by staining with the Alizarin Red S to visualize calcification deposits.

Cell viability analysis. hADSCs were transfected with miRNA or siRNA. After $48 \mathrm{~h}$ incubation, cells were seeded in 12-well plates at a density of $8 \times 10^{4}$ cells/well. On the following day, confluent cells were treated with $\mathrm{CoCl}_{2}$ or SIN-1 for $20 \mathrm{~h}$, trypsinized and stained with trypan blue (Sigma). The number of viable and dead cells was counted using the Countess Automated Cell Counter.

Cell-cycle analysis. hADSCs were harvested and fixed with $70 \%$ ethanol. After extensive washing with HBSS, the cells were suspended in HBSS containing RNase A and PI (Sigma). The cells were incubated for $30 \mathrm{~min}$ at $37^{\circ} \mathrm{C}$ before flow-cytometric analysis using a FACS Canto II instrument (BD, San Jose, CA, USA) and the acquired data were analyzed using the FlowJo software (Tree Star, Ashland, OR, USA).

Annexin V staining assays for apoptosis. For Annexin $V$ staining assays, cells were stained with Annexin V-FITC and PI, and evaluated for apoptosis by flow cytometry according to the manufacturer's protocol (BD). The apoptotic cells were determined using a FACS Canto II instrument (BD).

Assay for intracellular ROS detection. Intracellular ROS production was measured with $\mathrm{H}_{2}$-DCFDA (Molecular Probes, Eugene, OR, USA) staining as described according to the manufacturer's instructions. Briefly, cells were preincubated with $\mathrm{H}_{2}$-DCFDA for 30 min in $5 \% \mathrm{CO}_{2}$ environment at $37^{\circ} \mathrm{C}$. After preincubation step, the cells were treated with $\mathrm{CoCl}_{2}$ or SIN-1 for $20 \mathrm{~h}$, floating and adherent cells were collected. Changes in fluorescence intensity of each sample were measured by the FACS Canto II instrument and analyzed by flow-cytometric analysis using the FlowJo software.

Real-time PCR. Total cellular RNA was extracted with TRlzol reagent (Invitrogen), followed by a reverse transcription with cDNA synthesis kit (Promega, Madison, WI, USA). Small RNA species-enriched RNA isolation was performed as per manufacturer's instructions (mirVana miRNA isolation kit; Ambion, Austin, TX, USA). miRNA was reverse transcribed using the Ncode miRNA first-strand cDNA synthesis kit (Invitrogen), according to the manufacturer's specified guidelines. Quantitative RT-PCR analysis was performed using SYBR Green PCR Master Mix on ABI 7500 system (Applied Biosystems, Warrington, UK).

Western blot analysis. Samples were homogenized in RIPA buffer (Sigma).The isolated proteins were separated by SDS-PAGE and electrotransferred onto PVDF membranes (Millipore, Bedford, MA, USA). Blots were probed with primary antibodies, followed by HRP-conjugated secondary antibodies. Antibodies used in this study were purchased as indicated: Bad, Bak, Bax, Bcl-2, Bcl- $\mathrm{X}_{\mathrm{L}}$, Keap1 and p21 from Santa Cruz Biotechnology (Dallas, TX, USA); Nrf-2 and p-Nrf-2 from Abcam (Cambridge, MA, USA); HO-1 from Enzo life sciences(Farmingdale, NY, USA); GAPDH from Cell Signaling Technologies 
(Boston, MA, USA). Bound antibodies were detected using an ECL detection kit (Pierce Biotechnology, Rockford, IL, USA) and visualized using LAS 3000 Luminoimage Analyzer (Fujfilm, Tokyo, Japan).

Microarray analysis. Total RNA was extracted with TRIzol (Invitrogen) and purified using RNeasy columns (Qiagen, Hilden, Germany) according to the manufacturer's instructions. Microarray analysis was carried out by Macrogen Inc. (Seoul, Korea). Briefly, biotinylated complementary RNAs were amplified and purified using the Ambion Illumina RNA amplification kit (Ambion) according to the manufacturer's instructions. Labeled cRNA samples were hybridized to each human HT-12 expression v. 4 bead array according to the manufacturer's instructions (Illumina, SanDiego, CA, USA). Detection of array signal was carried out using Amersham fluoroLink streptavidin-Cy3 (GE Healthcare Bio-Sciences, Uppsala, Sweden). Arrays were scanned with an Illumina bead array Reader confocal scanner, and the raw data were extracted using the software provided by the manufacturer (Illumina GenomeStudio v2011.1 (Gene Expression Module v1.9.0)).

Reporter vectors and DNA constructs. A putative miR-302d-recognition element (as single copy) from the CDKN1A or CCL5 gene was cloned in the 3'- UTR of the firefly luciferase reporter vector according to the manufacturer's specified guidelines. The oligonucleotide sequences were designed to carry the HindllI and Spel sites at their extremities facilitating ligation into the HindllI and Spel sites of pMIR-Report (Ambion). The oligonucleotides used in these studies were pMIR-CDKN1A FW, 5'-CTAGTTTCTTTTTCATTTGAGAAGTAAACAGATGG CACTTTGAAGGGGCCTCACCGA-3', RV, 5'-AGCTTCGGTGAGGCCCCTTCAAA GTGCCATCTGTTTACTTCTCAAATGAAAAAGAAA-3'; pMIR-CDKN1A mut FW, 5'-CTAGTTTCTTTTTCATTTGAGAAGTCCCACGATGTACAGGTGAAGGGGCCT CACCGA-3', RV, 5'-AGCTTCGGTGAGGCCCCTTCACCTGTACATCGTGGGACT TCTCAAATGAAAAAGAAA-3'; pMIR-CCL5 FW, 5'-CTAGTGGCTGGACGTGGTG GCTCACGCCTGTAATCCCAGCACTTTGGGAGGCCAAGA-3' RV, 5' -AGCTTCT TGGCCTCCCAAAGTGCTGGGATTACAGGCGTGAGCCACCACGTCCAGCCA-3' pMIR-CCL5 mut FW, 5'-CTAGTGGCTGGACGTGGTGTAGACCGACGTTCATCC

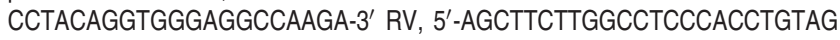
GGGATGAACGTCGGTCTACACCACGTCCAGCCA-3'.

Reporter gene assay. Luciferase reporter assay was performed using Luciferase Assay System (Promega) according to the manufacturer's specified guidelines. Briefly, DharmaFECT Duo Transfection Reagent (Thermo Scientific, Epsom, UK) was used for cotransfection of reporter plasmid and miRNA mimic. The pMIR-CDKN1A or pMIR-CCL5 and pMIR- $\beta$-gal plasmids were used as reporter constructs. The cells were harvested $72 \mathrm{~h}$ after transfection, lysed in RLB buffer, and subsequently assayed for their luciferase activity by Victor3 Multilabel Plate Reader (Perkin-Elmer, Waltham, MA, USA). The transfections were performed in duplicate, and all experiments were repeated several times. The luciferase assays were normalized according to their $\beta$-galactosidase activity.

ELISA. The cell-culture supernatants from hADSCs were subjected to ELISA. The secretion of CCL5 was measured with commercially available ELISA kits (R\&D Systems) according to the manufacturer's instructions. The absorbance $(450 \mathrm{~nm})$ for each sample was analyzed using Sunrise Microplate Reader (TECAN SUNRISE, Männedorf, Switzerland).

Statistical analysis. Data are presented as the mean \pm S.D. of independent experiments with similar results. Statistical comparisons between experimental groups were performed with ANOVA test or two-tailed Student's $t$-test. $P<0.05$ was considered as statistically significant.

\section{Conflict of Interest}

The authors declare no conflict of interest.

Acknowledgements. This study was supported by the National Research Foundation of Korea (NRF) grant founded by the Korea Government (MSIP; 2012M3A9B4028558) and the MRC program of MEST/KOSEF (2007-0052078).

1. Bartel DP. MicroRNAs: genomics, biogenesis, mechanism, and function. Cell 2004; 116 : 281-297.
2. Nelson P, Kiriakidou M, Sharma A, Maniataki E, Mourelatos Z. The microRNA world: small is mighty. Trends Biochem Sci 2003; 28: 534-540.

3. Lee RC, Feinbaum RL, Ambros V. The C. elegans heterochronic gene lin-4 encodes small RNAs with antisense complementarity to lin-14. Cell 1993; 75: 843-854.

4. Johnston RJ, Hobert O. A microRNA controlling left/right neuronal asymmetry in Caenorhabditis elegans. Nature 2003; 426: 845-849.

5. Esquela-Kerscher A, Slack FJ. Oncomirs - microRNAs with a role in cancer. Nat Rev Cancer 2006; 6: 259-269.

6. Lin SL, Chang DC, Chang-Lin S, Lin CH, Wu DT, Chen DT et al. Mir-302 reprograms human skin cancer cells into a pluripotent ES-cell-like state. RNA 2008; 14: 2115-2124.

7. Lin SL, Chang DC, Lin CH, Ying SY, Leu D, Wu DT. Regulation of somatic cell reprogramming through inducible mir-302 expression. Nucleic Acids Res 2011; 39: 1054-1065.

8. Subramanyam D, Lamouille S, Judson RL, Liu JY, Bucay N, Derynck R et al. Multiple targets of miR-302 and miR-372 promote reprogramming of human fibroblasts to induced pluripotent stem cells. Nat Biotechnol 2011; 29: 443-448.

9. Miyoshi N, Ishii H, Nagano H, Haraguchi N, Dewi DL, Kano $\mathrm{Y}$ et al. Reprogramming of mouse and human cells to pluripotency using mature microRNAs. Cell Stem Cell 2011; 8: 633-638.

10. Kumar MG, Patel NM, Nicholson AM, Kalen AL, Sarsour EH, Goswami PC. Reactive oxygen species mediate microRNA-302 regulation of AT-rich interacting domain $4 \mathrm{a}$ and $\mathrm{C}-\mathrm{C}$ motif ligand 5 expression during transitions between quiescence and proliferation. Free Radic Biol Med 2012; 53: 974-982.

11. Kang H, Louie J, Weisman A, Sheu-Gruttadauria J, Davis-Dusenbery BN, Lagna G et al. Inhibition of microRNA-302 (miR-302) by bone morphogenetic protein 4 (BMP4) facilitates the BMP signaling pathway. J Biol Chem 2012; 287: 38656-38664.

12. Lipchina I, Elkabetz Y, Hafner M, Sheridan R, Mihailovic A, Tuschl T et al. Genome-wide identification of microRNA targets in human ES cells reveals a role for miR-302 in modulating BMP response. Genes Dev 2011; 25: 2173-2186.

13. Lin SL, Chang DC, Ying SY, Leu D, Wu DT. MicroRNA miR-302 inhibits the tumorigenecity of human pluripotent stem cells by coordinate suppression of the CDK2 and CDK4/6 cell cycle pathways. Cancer Res 2010; 70: 9473-9482.

14. Barroso-delJesus A, Lucena-Aguilar G, Sanchez L, Ligero G, Gutierrez-Aranda I, Menendez $P$. The Nodal inhibitor Lefty is negatively modulated by the microRNA miR-302 in human embryonic stem cells. FASEB J 2011; 25: 1497-1508.

15. Hu S, Wilson KD, Ghosh Z, Han L, Wang Y, Lan F et al. MicroRNA-302 increases reprogramming efficiency via repression of NR2F2. Stem Cells 2013; 31: 259-268.

16. Zuk PA, Zhu M, Ashjian P, De Ugarte DA, Huang Jl, Mizuno $\mathrm{H}$ et al. Human adipose tissue is a source of multipotent stem cells. Mol Biol Cell 2002; 13: 4279-4295.

17. Rodriguez AM, Elabd C, Amri EZ, Ailhaud G, Dani C. The human adipose tissue is a source of multipotent stem cells. Biochimie 2005; 87: 125-128.

18. Gimble JM, Guilak F. Differentiation potential of adipose derived adult stem (ADAS) cells. Curr Top Dev Biol 2003; 58: 137-160.

19. Kim YJ, Bae SW, Yu SS, Bae YC, Jung JS. miR-196a regulates proliferation and osteogenic differentiation in mesenchymal stem cells derived from human adipose tissue. $J$ Bone Miner Res 2009; 24: 816-825.

20. Kim YJ, Hwang SH, Cho HH, Shin KK, Bae YC, Jung JS. MicroRNA 21 regulates the proliferation of human adipose tissue-derived mesenchymal stem cells and high-fat diet-induced obesity alters microRNA 21 expression in white adipose tissues. J Cell Physiol 2012; 227: 183-193.

21. Koopman G, Reutelingsperger CP, Kuijten GA, Keehnen RM, Pals ST, van Oers MH. Annexin $V$ for flow cytometric detection of phosphatidylserine expression on $B$ cells undergoing apoptosis. Blood 1994; 84: 1415-1420.

22. Kaspar JW, Niture SK, Jaiswal AK. Nrf2:INrf2 (Keap1) signaling in oxidative stress. Free Radic Biol Med 2009; 47: 1304-1309.

23. Ryter SW, Choi AM. Heme oxygenase-1/carbon monoxide: from metabolism to molecular therapy. Am J Respir Cell Mol Biol 2009; 41: 251-260.

24. Macip S, Igarashi M, Fang L, Chen A, Pan ZQ, Lee SW et al. Inhibition of p21-mediated ROS accumulation can rescue p21-induced senescence. EMBO J 2002; 21: 2180-2188.

25. Besson A, Dowdy SF, Roberts JM. CDK inhibitors: cell cycle regulators and beyond. Dev Cell 2008; 14: 159-169.

26. Satriano JA, Banas B, Luckow B, Nelson P, Schlondorff DO. Regulation of RANTES and ICAM-1 expression in murine mesangial cells. J Am Soc Nephrol 1997; 8: 596-603.

27. Kapp A, Zeck-Kapp G, Czech W, Schopf E. The chemokine RANTES is more than a chemoattractant: characterization of its effect on human eosinophil oxidative metabolism and morphology in comparison with IL-5 and GM-CSF. J Invest Dermatol 1994; 102: 906-914.

28. Wang L, Yao J, Shi X, Hu L, Li Z, Song T et al. MicroRNA-302b suppresses cell proliferation by targeting EGFR in human hepatocellular carcinoma SMMC-7721 cells. BMC Cancer 2013; 13: 2407-13-448.

29. Cai N, Wang YD, Zheng PS. The microRNA-302-367 cluster suppresses the proliferation of cervical carcinoma cells through the novel target AKT1. RNA 2013; 19: 85-95.

30. Fareh M, Turchi L, Virolle V, Debruyne D, Almairac F, de-la-Forest Divonne $S$ et al. The miR 302-367 cluster drastically affects self-renewal and infiltration properties of glioma-initiating cells through CXCR4 repression and consequent disruption of the SHH-GLI-NANOG network. Cell Death Differ 2012; 19: 232-244.

31. Card DA, Hebbar PB, Li L, Trotter KW, Komatsu Y, Mishina Y et al. Oct4/Sox2-regulated miR302 targets cyclin D1 in human embryonic stem cells. Mol Cell Biol 2008; 28: 6426-6438. 
32. Rizzo M, Mariani L, Pitto L, Rainaldi G, Simili M. miR-20a and miR-290, multi-faceted players with a role in tumourigenesis and senescence. J Cell Mol Med 2010; 14: 2633-2640.

33. Chen CZ, Li L, Lodish HF, Bartel DP. MicroRNAs modulate hematopoietic lineage differentiation. Science 2004; 303: 83-86.

34. Poliseno L, Pitto L, Simili M, Mariani L, Riccardi L, Ciucci A et al. The proto-oncogene LRF is under post-transcriptional control of MiR-20a: implications for senescence. PLoS One 2008; 3: e2542.

35. Pitto L, Rizzo M, Simili M, Colligiani D, Evangelista M, Mercatanti A et al. miR-290 acts as a physiological effector of senescence in mouse embryo fibroblasts. Physiol Genomics 2009; 39: $210-218$.

36. He L, Thomson JM, Hemann MT, Hernando-Monge E, Mu D, Goodson S et al. A microRNA polycistron as a potential human oncogene. Nature 2005; 435: 828-833.

37. Marson A, Levine SS, Cole MF, Frampton GM, Brambrink T, Johnstone S et al. Connecting microRNA genes to the core transcriptional regulatory circuitry of embryonic stem cells. Cell 2008; 134: 521-533.

38. Gartel AL, Radhakrishnan SK. Lost in transcription: p21 repression, mechanisms, and consequences. Cancer Res 2005; 65: 3980-3985.

39. Chang HM, Martinez NJ, Thornton JE, Hagan JP, Nguyen KD, Gregory RI. Trim71 cooperates with microRNAs to repress Cdkn1a expression and promote embryonic stem cell proliferation. Nat Commun 2012; 3: 923.

40. Dolezalova D, Mraz M, Barta T, Plevova K, Vinarsky V, Holubcova Z et al. MicroRNAs regulate $\mathrm{p} 21$ (Waf1/Cip1) protein expression and the DNA damage response in human embryonic stem cells. Stem Cells 2012; 30: 1362-1372.

41. Murooka TT, Rahbar R, Fish EN. CCL5 promotes proliferation of MCF-7 cells through mTORdependent mRNA translation. Biochem Biophys Res Commun 2009; 387: 381-386.

42. Zou W, Yan M, Xu W, Huo H, Sun L, Zheng Z et al. Cobalt chloride induces PC12 cells apoptosis through reactive oxygen species and accompanied by AP-1 activation. J Neurosci Res 2001; 64: 646-653.

43. Chachami G, Simos G, Hatziefthimiou A, Bonanou S, Molyvdas PA, Paraskeva E. Cobalt induces hypoxia-inducible factor-1alpha expression in airway smooth muscle cells by a reactive oxygen species- and PI3K-dependent mechanism. Am J Respir Cell Mol Biol 2004; 31: 544-551.

44. Darley-Usmar VM, Hogg N, O'Leary VJ, Wilson MT, Moncada S. The simultaneous generation of superoxide and nitric oxide can initiate lipid peroxidation in human low density lipoprotein. Free Radic Res Commun 1992; 17: 9-20.

45. Pulukuri SM, Rao JS. Activation of p53/p21Waf1/Cip1 pathway by 5-aza-2'-deoxycytidine inhibits cell proliferation, induces pro-apoptotic genes and mitogen-activated protein kinases in human prostate cancer cells. Int J Oncol 2005; 26: 863-871.

46. Hastak K, Agarwal MK, Mukhtar H, Agarwal ML. Ablation of either p21 or Bax prevents p53-dependent apoptosis induced by green tea polyphenol epigallocatechin-3-gallate. FASEB J 2005; 19: 789-791.
47. Fujiwara K, Daido S, Yamamoto A, Kobayashi R, Yokoyama T, Aoki H et al. Pivotal role of the cyclin-dependent kinase inhibitor p21WAF1/CIP1 in apoptosis and autophagy. J Biol Chem 2008; 283: 388-397.

48. Wu YC, O'Reilly MA. Bcl- $X(L)$ is the primary mediator of p21 protection against hyperoxia-induced cell death. Exp Lung Res 2011; 37: 82-91.

49. Rodriguez R, Meuth M. Chk1 and p21 cooperate to prevent apoptosis during DNA replication fork stress. Mol Biol Cell 2006; 17: 402-412.

50. Ahn J, Won M, Choi JH, Kim YS, Jung CR, Im DS et al. Reactive oxygen species-mediated activation of the Akt/ASK1/p38 signaling cascade and p21(Cip1) downregulation are required for shikonin-induced apoptosis. Apoptosis 2013; 18: 870-881.

51. Casola A, Burger N, Liu T, Jamaluddin M, Brasier AR, Garofalo RP. Oxidant tone regulates RANTES gene expression in airway epithelial cells infected with respiratory syncytial virus. Role in viral-induced interferon regulatory factor activation. J Biol Chem 2001; 276: 19715-19722.

52. Braunersreuther V, Pellieux C, Pelli G, Burger F, Steffens S, Montessuit C et al. Chemokine CCL5/RANTES inhibition reduces myocardial reperfusion injury in atherosclerotic mice. J Mol Cell Cardiol 2010; 48: 789-798.

53. Chaudhari $P, Y e Z$, Jang $Y Y$. Roles of reactive oxygen species in the fate of stem cells. Antioxid Redox Signal 2012; 20: 1881-1890.

54. Crespo FL, Sobrado VR, Gomez L, Cervera AM, McCreath KJ. Mitochondrial reactive oxygen species mediate cardiomyocyte formation from embryonic stem cells in high glucose. Stem Cells 2010; 28: 1132-1142.

55. Kim Y, Kim H, Cho H, Bae Y, Suh K, Jung J. Direct comparison of human mesenchymal stem cells derived from adipose tissues and bone marrow in mediating neovascularization in response to vascular ischemia. Cell Physiol Biochem 2007; 20 : $867-876$

(c) $\$ \Theta$ Cell Death and Disease is an open-access journal BY NC ND published by Nature Publishing Group. This work is licensed under a Creative Commons Attribution-NonCommercialNoDerivs 3.0 Unported License. The images or other third party material in this article are included in the article's Creative Commons license, unless indicated otherwise in the credit line; if the material is not included under the Creative Commons license, users will need to obtain permission from the license holder to reproduce the material. To view a copy of this license, visit http://creativecommons.org/licenses/ by-nc-nd/3.0/

Supplementary Information accompanies this paper on Cell Death and Disease website (http://www.nature.com/cddis) 